\title{
Defect management of hospital buildings
}

\author{
AbdulLateef Olanrewaju ${ }^{1} \cdot$ Shao Han Tee ${ }^{1} \cdot$ Poh $\mathrm{Im} \mathrm{Lim}^{2} \cdot$ Wai Fang Wong ${ }^{3}$
}

Received: 2 November 2021 / Revised: 14 December 2021 / Accepted: 14 December 2021 / Published online: 24 December 2021

(c) The Author(s), under exclusive licence to Springer Nature Switzerland AG 2021

\begin{abstract}
Healthcare organisations are increasingly recognising the need to improve building performance in order to improve health care delivery, profits, and to reduce penalties. Hospital maintenance organisations are under constant pressure to plan maintenance work due to a shortage of funds on account of huge catalogues of defects in hospital buildings. While investments in hospital building maintenance are increasing, the requirement to increase building performance and user satisfaction is also increasing. The nature of building faults and the factors that influence hospital building maintenance management in Malaysia were explored. Primary data were collected through structured interview techniques involving six hospital maintenance organisations. According to the results of a survey interview involving six hospitals, water seepage, cracks, peeling paint, broken ironmongery, pipe leakage, damaged plasterboard, and discoloured paint are all widespread in hospital structures, according to the results of a survey interview involving six private and public hospitals. The key aspects that determine the maintenance management practise of hospital buildings are user attitudes, misuse/abuse, weather, and bad maintenance practice. The data revealed that hospital building users are demanding improved building performance through enhanced maintenance management service delivery. Implicit in the findings of this research is the lack of effective maintenance organisations. It is necessary to reorganise the hospital's maintenance organisations. From an ontological standpoint, the main findings of this study are generalizable to other hospitals and building typologies in and outside of Malaysia.
\end{abstract}

Keywords Building pathology $\cdot$ Maintenance organisation $\cdot$ Procurement $\cdot$ Value-added services $\cdot$ Malaysia

\section{Introduction}

This study is part of a larger study in Malaysia on building maintenance management strategies for hospitals. The overarching goal of the main research, of which this paper

AbdulLateef Olanrewaju

abdullateef.olanrewaju@ymail.com

Shao Han Tee

shaohan0422@yahoo.com

Poh Im Lim

limpi@utar.edu.my

Wai Fang Wong

wongwf@tarc.edu.my

1 Universiti Tunku Abdul Rahman, 31900 Kampar, Perak, Malaysia

2 Universiti Tunku Abdul Rahman, Sungai Long Campus, Jalan Sungai Long, Bandar Sungai Long, 43200 Kajang, Selangor, Malaysia

3 Tunku Abdul Rahman University College, 53300 Kuala Lumpur, Wilayah Persekutuan Kuala Lumpur, Malaysia reports part, is to establish a value-based hospital building maintenance management model. Value-based maintenance management (VBMM) is a decision-making framework for formulating building maintenance "activities" that involve both maintenance service providers and maintenance service users [1]. Its goal is to determine, assess, and recommend when, what, how, and where maintenance measures in a building are needed. Building pathology is an important part of the framework. The critical analysis of the origins, symptoms, impact, and solutions to remedy faults in structures is known as building pathology or defect management. As a result, understanding building pathology aid in extending the life of buildings. However, this article on the other hand, was written as a stand-alone. Specifically, this research is part of hospital building pathology that is concerned with investigating the nature of defects in hospital buildings and the factors leading to the maintenance management of hospital buildings, their causes, and potential remedies in a valuebased maintenance approach.

Buildings require maintenance to ensure their optimal performance over their life cycle. While new buildings are needed, 
buildings cannot remain new throughout their life span because of the finite nature of building materials and components. As buildings decay, it is not an effective solution to demolish and rebuild them as they consume many resources such as materials, energy, and labour [3]. Furthermore, building components decay at different rates and times. The scale of the problem increases from an individual building to a global built environment. The purposes of buildings depend primarily on the nature of the functional values of the building and the 'acceptable' level of defects in the building. Therefore, the need for building maintenance will intensify to preserve and sustain the functions of the building structures, finishes and decorations, fabrics, and engineering services. Building maintenance ensures that buildings are functional, long-lasting, dependable, and safe, as well as that building users are satisfied $[1,3]$. Although there is no clear literature on how effectively hospital buildings are maintained in Malaysia, media reports and academic literature indicate that the buildings are not well maintained [1-5]. Extant research revealed that the present approaches to hospital building maintenance in Malaysia are corrective, cycli$\mathrm{cal}$, and inspection-based. Maintenance refers to the processes and services undertaken in order to preserve, repair, protect, enhance, and care for the hospital building structure and services after completion, repair, refurbishment, or replacement to current standards so that it can serve its intended functions throughout its entire life span without drastically upsetting its basic features and use [6]. It is evident from this description that maintenance is a process or programme rather than a project, and that maintenance is initiated by the users rather than the building itself. In fact, the design, construction, and operation of hospital buildings have a profound impact on the users' health [7]. More than $90 \%$ of hospital activities take place within or near the buildings. Thus, any inadequacy in the building facilities will have some negative impact on hospital performance and purposes. Government expenditure on maintenance of the hospital buildings is huge, albeit decreasing. The total expenditure for maintenance (modification, upgrade and repair) dropped by $15.37 \%$ during the last 14 years [8] (Table 1).

The reduction in expenditure is happening when the buildings are aging, the numbers of users are increasing, and users are becoming more demanding and complicated [1,2]. Even though special funding is often provided to cater for the maintenance of the hospital buildings, the building maintenance organisations at the hospitals are under intense pressure to meet the maintenance demand and user value systems. However, there have been several complaints in the scientific literature and the media

Table 1 Distribution of respondent's highest academic qualification

\begin{tabular}{ll}
\hline Year & Actual expenditure (RM) \\
\hline $2006-2008$ & $299,933,168.00$ \\
$2011-2013$ & $253,827,753.00$ \\
$2016-2018$ & $236,591,194.00$ \\
\hline
\end{tabular}

in recent years regarding the poor state of hospital buildings [9-13], which stemmed from the lack of systemic maintenance being carried out on those buildings and infrastructures. Hence, the way the maintenance works and the activities are organised is critical and strategic. When maintenance demand arises, a decision has to be made whether to conduct maintenance or not. To arrive at a decision, several criteria require critical investigation. Therefore, to improve the performance of hospital buildings, maintenance management is increasingly becoming a major tool to reduce the maintenance backlog and increase the users' experience. Therefore, this research investigated the types of defects and evaluated the factors that affect the maintenance management of hospital buildings.

\section{Literature and theoretical framework}

The Malaysian health care industry is one of the most vibrant in the region. Malaysia was named one of the Best Health Care in the world by the International Living Annual Global Retirement Index in 2019. Malaysia has 114 public hospitals and 210 private hospitals in 2018. The building is one of the significant assets on the hospital's balance sheet. Hospital buildings are procured to provide an appropriate, conducive, and acceptable atmosphere in which patients can recover and medical specialists and non-medical employees can execute their tasks effectively $[1,2]$. Buildings, on the other hand, deteriorate, disintegrate, decay, and lose their economic and functional worth as a result of several circumstances. Furthermore, the buildings would degenerate at different rates and at different times which are often unanticipated. Furthermore, the buildings, users, the environment, and hospital organisations are all interconnected to the point where a failure in one chain has a substantial impact on the functioning of the buildings. Examination of this interaction is described as "building pathology." A failure to provide these critical services results in a loss for hospitals and customers. In fact, it has been argued that the environment (i.e., buildings) where patients receive treatment is far more effective at improving people's health than medical treatments $[7,14,15]$, confirming the importance of hospital buildings. As a result, a well-maintained building is essential for a hospital's corporate business objectives to be met. When a building's maintenance is not properly managed, it become more expensive to own or operate in the long run. While there is increasing research [16-23] on the conditions and performance of the hospital buildings, the studies, as well as government-sponsored assessments on the maintenance of hospital buildings in Malaysia, placed a strong emphasis on design and maintainability. A few studies have look into the facilities management of hospitals, but the unique consideration of the building maintenance management is critical and overwhelming. In support of this thesis, the rate of defects in hospital buildings is increasing unabated, especially as a result of poor maintenance 
management practises, as $[1,2]$ revealed, and despite the recognition of the impact of maintenance and maintenance management on the performance and condition of hospital buildings, research on maintenance management in hospitals in Malaysia is nascent. This study begins with dissatisfactions with the current maintenance management frameworks for Malaysian hospital buildings, with a focus on building investments on the one hand and user complaints on the other hand.

Building defects have been defined differently by different authors. A defect is an unfavourable or insufficient condition, appearance, or performance of a structure that has an impact on its usability. The primary causes of building defects are inevitably interconnected and complicated. Wear and tear, poor construction methods, poor material selection, poor workmanship, weather, and the age of the buildings could cause a defect [1]. This influences the serviceability, performance, acceptance, or appearance of the buildings or their combination. Except if a building wears out, is excessively neglected or vandalized, maintenance is the prominent solution that is required to restore the building to optimum operation. Otherwise, the building could require other initiatives, including refurbishment, conversion, rehabilitation, or reconstruction [6]. However, the major aims of the maintenance service are to delay defects and to sustain and improve the performance of buildings. A defect reduces the maintenance span of the building. The largest portion of the maintenance costs is attributable to identifying, preventing, and correcting defects. The impact of defect on the building's conditions, expression, and performance is determined by the building's functional requirements. For example, in the case of hospital buildings, a state that could be acceptable for a residential building may necessitate quick maintenance $[1,6]$. Perhaps the industries that place greater importance on the condition and performance of their buildings are hospital and hotel buildings. The reason for this is not difficult to explain. Some of the examples of defects in the building include cracked walls, decayed timber, decayed metal rails and pipes, sagging roofs, clogged water closets, faulty lifts, faulty windows and doors, leaking showers, water seepage, and sagging ceilings [2]. The maintenance span is the period between one repair and the next or previous repairs. The effective maintenance management framework, as explained, aims to increase the maintenance span of the buildings [1]. A shorter maintenance span reduce building availability and building performance and increase maintenance costs. Maintenance span impacts the user's satisfaction. Maintenance management entails planning, controlling, monitoring, engaging, and implementing maintenance resources to ensure that user and stakeholder value systems are delivered effectively and efficiently.

\subsection{Defects in the hospital buildings}

Building defects can be determined by the users of the maintenance organization. Maintenance costs and user happiness and productivity are affected by the defects in the buildings. Defect cause and aggrevates sickness for the users. In hospitals defects would even delay patients recovery. Defects must be controlled effectively and efficiently in order to assure building performance and user delight. Defect management is one of the prime functions of the maintenance organisation and is a strategic aspect of maintenance management. The analysis of the criteria that influence maintenance services determine when, what, and how maintenance services are provided, as well as how future work is scheduled and funded as part of the maintenance management rolling programme. In order to improve the service delivery of hospitals, active consideration of the factors that affect building maintenance is strategic functions is discussed at the board level by the senior management in the hospitals. The purpose of building maintenance management is to ensure the optimum performance of the buildings within budget, at the shortest minimum time, and with high quality. The maintenance management of hospital buildings is influenced by various factors [1, 2, 24-28]. The major aims of the maintenance service are to delay defects and to sustain and improve the performance of buildings. Delaying defects until such a stage that their impact is little or negligible on the organization's corporate business objectives has an effect on maintenance costs and on the profitability and productivity of hospital organizations.

Although there have been a few attempts to examine the maintenance aspect of hospital buildings in Malaysia, maintenance management requires further and continuing critical examinations. For instance, most of the previous research placed an emphasis on maintainability. Maintainability, however critical, is not maintenance-because building materials and components have finite lifespans $[1,3]$. Maintainability is primarily a design problem, and it relates to the ease with which a building can be maintained due to design concepts and the nature of the components and materials. Building materials deteriorate at different times and at different rates. During design and construction, designers and labourers are likely to make incorrect assumptions about weather and user behaviour, which cause the buildings to deteriorate differently. According to existing research, while cost of maintenance is the primary decision criterion for hospital building maintenance demand, the impact of user comfort, satisfaction, time, safety, reliability, and security is becoming increasingly important $[1,4,5]$. Even at that, most studies failed to examine the inclusion of the criteria in decision-making on maintenance demands, hence leading to fragmented and biased decisions [2, 3, 21]. However, Olanrewaju and AbdulAziz [6] identified and quantified the impacts of some of these criteria. Their findings, albeit expedient, did not draw empirical data from the hospital buildings, hence offering limited decision information to the 
hospital maintenance organisations. Recent research [4] that focused on the critical success factors for maintenance to enhance hospital buildings and to evaluate the causal relationships between value factors and value outcomes of building maintenance in public hospitals in Malaysia [5] is limited to public hospitals. Procedures to reduce defects in hospital buildings have also been investigated [2]. However, factors affecting building maintenance management require further and continuing examination.

\section{Research design}

The interview technique was used to acquire primary data. The interview process entails the interviewer asking questions and the interviewee replying to those questions [28, 29]. Interviews are categorised into three classes, namely, structured interviews, semi-structured interviews, and unstructured interviews. However, for this research, a structured interview was used to collect the data because it is consistent with the aim and objectives of this research. The structured interview is also known as a standardised interview. It promotes standardisation, which reduces errors caused by question variety. The structured interview approach is similar to the standard survey questionnaire method. For instance, the structured method resembles a checklist type of observation research in which the interviewer completes the questionnaire, not the interviewee, and the questions are generally closed-ended. However, unlike the standard survey questionnaire approach, probing is often involved in a structured interview. Probing is a situation where the interviewer pose follow-up questions for further clarification where necessary from the interviewee. The survey interview form and cover letter were sent to 85 private hospitals and 34 public hospitals through emails. The selection of hospitals was based on convenient sampling. The emails were sent from July through August 2020. The long period of survey duration was a result of the poor response rate. The COVID-19 outbreak also contributed to the long survey period. A number of hospitals were forced to close as a result of the epidemic.

The interviewees were presented with a list containing 20 building defects that were derived from literature and discussion with those concerned with the maintenance management of hospital buildings. The interviewees were asked to distinguish which of the defects were prevalent in the hospital buildings based on their prevailing experiences. Similarly, 15 factors that can affect the maintenance management of hospital buildings were addressed to the interviewees. Interviewees were asked to identify the factors that affect the maintenance management of the buildings in their portfolio. The cover letter and the survey form were directed at the most senior person in the maintenance organisation. The common intent is the same, regardless of the names given to the roles of the maintenance manager (maintenance executive, property manager, or general manager) or the maintenance organisations (asset management division, facility management unit, property management department, or development division) [6]. Generally, one person or organisation is in charge of overseeing and controlling the activities of the numerous personal or departmental units inside the company. The questionnaires were directed exclusively at the hospital's "maintenance managers." The maintenance manager in hospital maintenance organisations was postulated to be the best person to respond to the questionnaire because they are the ones who are involved in the strategic decision-making processes on the maintenance management of the hospital buildings. The managers are not only involved in establishing the goals and objectives of the organisations but also make sure that the day-to-day operations of the organizations run smoothly. A total of 119 invitations were sent to maintenance organizations. However, by the deadline, nine respondents had accepted to participate in the study. Due to government restrictions to control the scourge of the COVID-19 pandemic, only six participated in the interviews. Following Olanrewaju, et al.'s [30], the following questions were developed to guide the interview sessions.

(a) Position

(b) Working experience (current hospital)

(c) Size of maintenance organization

(d) The age of the hospital building

(e) The size of the hospital building

(f) Factors determining the maintenance of hospital buildings

(g) Defects in this hospital building

(h) Insource or outsource, which is carried and why?

\section{Analysing the results of the interviews}

The interviews took place on the hospital premises. Five of the interviewees were interviewed in July 2020, and the final one in August 2020.

\subsection{Respondent's profile}

Table 2 contains the breakdowns of the interviewees' backgrounds. Hospital $\mathrm{C}$ has 2 mechanical engineers, 2 electrical engineers, 1 head of department, 6 assistants, and 2 engineers; Hospital D has 1 head of department, 2 biomedical engineers, 1 supervisor, 4 technicians, and 1 clerk; Hospital E has 1 biomedical, Facilities and Maintenance Division Manager, 1 person in charge of Housekeeping, Laundry, 
Table 2 Distribution of respondent's profile

\begin{tabular}{|c|c|c|c|c|c|c|}
\hline Hospital & Types of hospital & Position & $\begin{array}{l}\text { Working expe- } \\
\text { rience }\end{array}$ & $\begin{array}{l}\text { Size of maintenance } \\
\text { organization }\end{array}$ & Age & Area of building \\
\hline A & Private & Civil Engineer & 7 years & 1 & 50 years & $580.46 \mathrm{~m}^{2}$ \\
\hline B & Private & Civil Engineer & 5 years & 19 & 5 years & $121,893.40 \mathrm{~m}^{2}$ \\
\hline $\mathrm{C}$ & Private & Electrical Engineer & 5 years & 13 & 150 years & $277,000.00 \mathrm{~m}^{2}$ \\
\hline $\mathrm{D}$ & Public & $\begin{array}{l}\text { Head of Maintenance } \\
\text { Department }\end{array}$ & 3 years & 9 & 9 years & $32,840.71 \mathrm{~m}^{2}$ \\
\hline $\mathrm{E}$ & Public & $\begin{array}{l}\text { Biomedical Engineer } \\
\text { Officer }\end{array}$ & $\begin{array}{l}5 \text { years } \\
4 \text { years }\end{array}$ & 28 & 116 years & $7860.00 \mathrm{~m}^{2}$ \\
\hline $\mathrm{F}$ & Public & Project Director & 2 years & - & 11 years & $21,860.09 \mathrm{~m}^{2}$ \\
\hline
\end{tabular}

Clinical Waste and Outsource, 1 person in charge of Safety, Health and Environment, 1 person in charge of high temperature and mechanical work, 1 person in charge of electrical, civil and landscape, 1 person in charge of Biomedical and Project with 5 assistants, and 1 person is in charge of the Imaging Department with 7 assistants; and 1 person in charge of the IT Department with 1 assistant. Figures 1 and 2 show examples of organisational charts for a private and public hospital, respectively. The average area of the hospital building (gross floor area of the 6 hospitals) is 77,005.78 $\mathrm{m}^{2}$. The average age of the buildings is about 60 years old, and the average working experience of the interviewees is approximately 4 years. Based on these profiles, it is obvious that the interviewees have accurate information on the nature of hospital building maintenance.
Setting up a maintenance organisation that earns value for money requires complex thought processes. Maintenance managers and staff must have knowledge of maintenance management skills to support the anticipated workload and resources. Maintenance must be initiated based on users' needs and the value system. The findings imply that most hospitals prefer to use outside contractors for provide the maintenance services. There is little clear evidence that either private or public hospitals have large maintenance departments. However, there are obvious distinctions between the two categories. In comparison to privately owned hospitals, public hospitals have a more organised and devoted maintenance organisation, despite the fact that private hospitals spend nearly 5 times as much on maintenance as public hospitals. However, many of the maintenance

Fig. 1 Organisation of hospital (private)

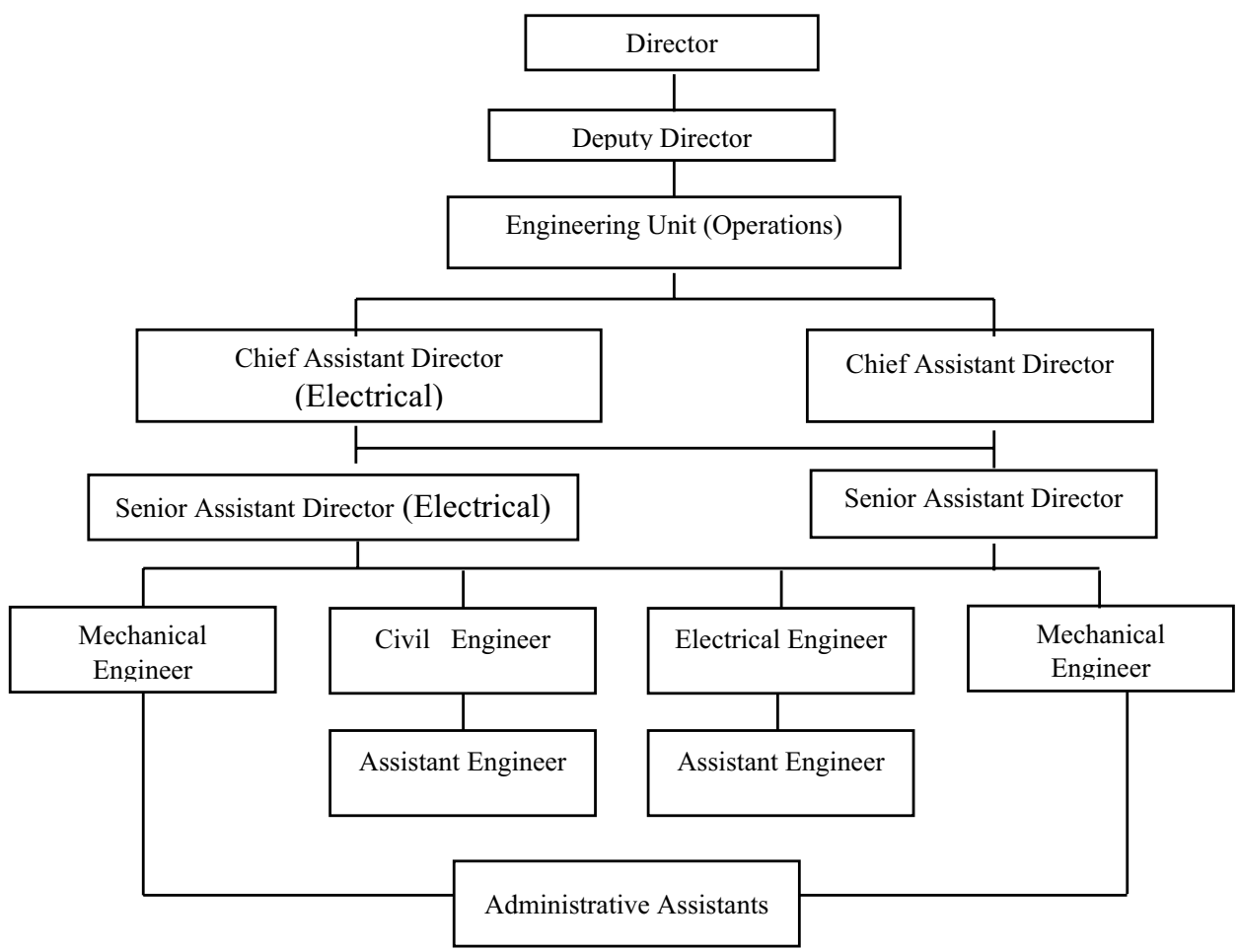


Fig. 2 Organisation hospital (public)

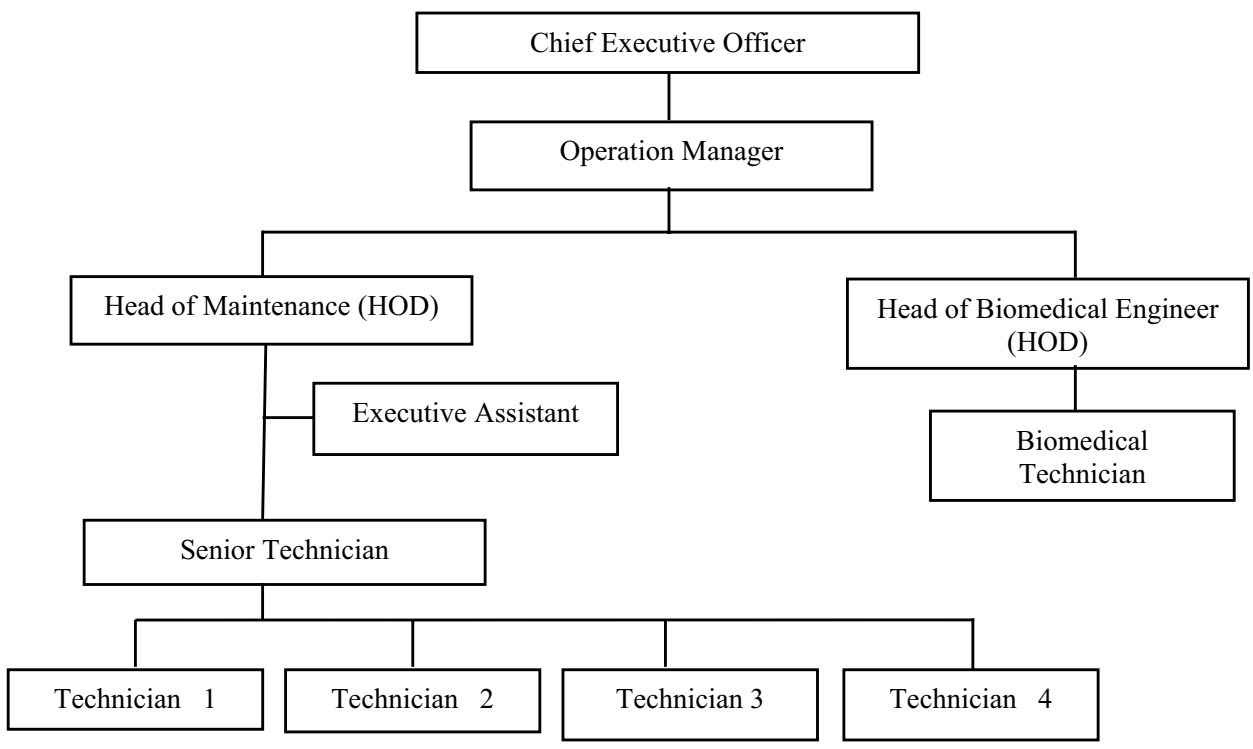

activities in public hospitals are outsourced (Table 3 ). This may not be surprising because hospital organisations estimate that building performance is not their core service. As such, most hospital organisations outsource a significant portion of their maintenance services. Effectively, hospitals have downsized building functions, making the in-house maintenance organisation less competent and unable to have proper knowledge transfer/management. However, as Olanrewaju et al. [1, 2] explained, building maintenance is a core service of hospitals and should not be outsourced. A plausible reason why most organisations outsource the maintenance of their buildings is that they believe building maintenance is a necessary evil that cost what it cost regardless of the measures taken to prevent and control it [6]. Many hospital organisations consider building maintenance as a non-core activity of hospitals. On the face of it, this might seem correct. However, with buildings accounting for more than $50 \%$ of most hospitals' assets, it is systemic for the hospital building maintenance organisation to rethink the procurement of the maintenance services and to rethink the structure of the maintenance organizations. There is a strategic need for hospital organisations to rethink building performance by measuring investment in building maintenance as value-added services to the hospital organizations. Hospital organisations should developed maintenance organisations that are specifically dedicated to the hospital. Resources should be put into improving the knowledge base of maintenance organizations. Refresher courses should be provided to the staff of the maintenance organisations. Only specialised repairs should be outsourced. Maintenance management functions should not be seen as tactical functions but strategic ones that contribute significantly to the hospital's corporate mission and vision. Although most private hospitals are recognising this through an increase in maintenance expenditure, unfortunately, most of the maintenance services are not being conducted by the in-house maintenance organization. In fact, as Table 3 revealed, the in-house maintenance organisations are involved in only minor repairs, which are mainly tactical functions. This is also obvious in Table 2, as there is no correlation between
Table 3 Defects categorized to in-source and out-source

\begin{tabular}{ll}
\hline Hospital & Answer \\
\hline A & Outsource company will responsible for all defects no matter minor or major defects \\
$\mathrm{B}$ & In-source: crack, lighting problem, pipe leakage \\
& Out-source: painting, electrical wiring, breakdown of air conditioning \\
$\mathrm{C}$ & Insource: cracks, pipe leaking, damaged of ironmongery \\
& Out source: underground pipe leakage, painting, electrical wiring \\
$\mathrm{D}$ & Insource: crack, pipe leakage, water leakage, paint \\
& Out-source: services on air-conditioning motor, chiller, ceiling \\
$\mathrm{E}$ & In-source: damaged of ironmongery, pipe leakage, paint \\
& Out-source: rusting of rooftop, big crack, ceiling peel off and drop \\
$\mathrm{F}$ & In-source: damaged of ironmongery, water leakage, furniture damage \\
& Out-source: air-conditioning maintenance, roof leaking, lift maintenance, cleaning \\
\hline
\end{tabular}


the maintenance organisation and the building age and size of the buildings. This is also reflected in the position of those responsible for the maintenance organization. In fact, most of the 'maintenance managers' do not have the academic background suitable for maintenance management [6]. The maintenance organisations should be entrepreneur-lead. Investment in new hospital buildings should involve the active participation of the maintenance organization. This would reduce future maintenance costs and the "Cinderella syndrome" plaguing the maintenance industry in particular and the construction sector.

\subsection{Analyses and discussion of defects in hospital buildings}

The climate in Malaysia is tropical, with temperatures ranging between $28^{\circ} \mathrm{C}\left(82^{\circ} \mathrm{F}\right)$ and $32^{\circ} \mathrm{C}\left(89^{\circ} \mathrm{F}\right)$ during the day. The humidity is high, ranging from 85 to $90 \%$. Hospital buildings in Malaysia are characterised by frame structures, solid and hollow bricks/masonry, cement and sand mortar beds, and joints. The windows and doors are in metal, or glass and aluminium, with timber and steel joinery. The roofs of the structures are mostly made of bricks, slates or aluminium sheets. On the screeded bed, the floors are mostly decorated with ceramic and marble tiles. Ceramic wares were used for sanitary equipment and fittings. The walls are plastered and rendered in cement and sand, prepared for emulsion painting. Deductively, the hospital maintenance organisations manage an extensive array of buildings. Table 4 contains a summary of the types of defects in the hospital buildings. Figure 2 displays examples of defects in hospital buildings. The findings on the types of defects are similar to the previous findings [21-23, 31, 32]. The interviewees ranked water seepage as one of the most repulsive defects in hospital buildings. Water seepage is the movement of water through building elements like walls, floors, and columns into the buildings or/from the outside of adjoining buildings. Water seepage is more common in the basements. The most common cause of water leakage in buildings is pipe leakage, which results from decayed building elements and building elements. This is, often due to poor maintenance. Because pipes are common in hospitals, various types of leakage may be anticipated. However, as may be observed, it may be tempting to argue that the age of a building is a major cause of the seepage of a hospital (Fig. 3). A collapsed drain could also lead to water seepage. Water seepage could result from cracks in walls and floors or pipe leakage. Water seepage and cracks may lead to peeling of paint on the walls and ceilings, defective plaster rendering, and fungi/algae attack. However, with good maintenance management practice, water seepage could be prevented.

Cracks in walls and floors are also prevalent in hospital buildings. Cracks in building elements are caused by the results of various agents. For example, cracks may be due
Table 4 Summary of defects in hospital buildings

\begin{tabular}{lll}
\hline Defects & Number & Number of hospitals \\
\hline Dampness & 2 & C, E \\
Water seepage & 6 & A, B, C, D, E, F \\
Cracks & 6 & A, B, C, D, E, F \\
Paint peeling & 6 & A, B, C, D, E, F \\
Damaged of ironmongery & 6 & A, B, C, D, E, F \\
Pipe leakage & 6 & A, B, C, D, E, F \\
Plaster board damage & 6 & A, B, C, D, E, F \\
Discoloured paint & 6 & A, B, C, D, E, F \\
Defective plaster rendering & 3 & A, C, E \\
Fangus/Algae & 3 & C, E, F \\
Detached of floor tiles & 3 & A, C, E \\
Settlement & 3 & A, E, F \\
Breaking of roof tiles & 2 & C, E \\
Ceiling peel off & 2 & C, E \\
Floor trap clogging & 2 & A, D \\
Tiles breaking & 2 & A, E \\
Deterioration of concrete and wood & 3 & A, C, F \\
\hline
\end{tabular}

to the age of buildings, land settlement, sway, vibration, poor construction practice, poor workmanship, and poor materials. Buildings require maintenance regardless of the quality of the materials and labour used. It is interesting that ground settlements were noticed in some of the hospitals. During construction, measures including proper site selection, reducing the load of the building, and using quality materials are necessary. However, the solutions to cracks during the operation stage of the building are effective maintenance management practises. It is interesting to find that pipe leakage is a major defect in the hospitals. Collapsed drain could be very disturbing. Aside from the fact that the drain may be usable, it produces offensive odours. Pipe disruptions could result from ground movement or even movement of walls, floors, beams, or columns. Concurrently, pipe leakage is ranked highly by the interviewees. Clogged water closets and pipe leakage often cause disruptions and frustration in toilets and bathrooms. Damaged walls were measured by the interviewees as frequent. Painting may peel from various building elements for a number of reasons. Painting on a dirty/wet surface, humidity/condensation, temperature, water seepage, and poor materials/paints are some of the main causes of painting peeling. Many of the causes of the paint peeling can be rectified with effective maintenance practices. Paint peeling like dampness, water seepage, pipe leakage, and fungus attacks are irritating and unsightly. It may lead to sick building syndrome. Damaged ironmongeries are common in hospitals. This finding may be expected due to heavy use and misuse, especially by family members of the patients. The interviewee for Hospital B mentioned that 


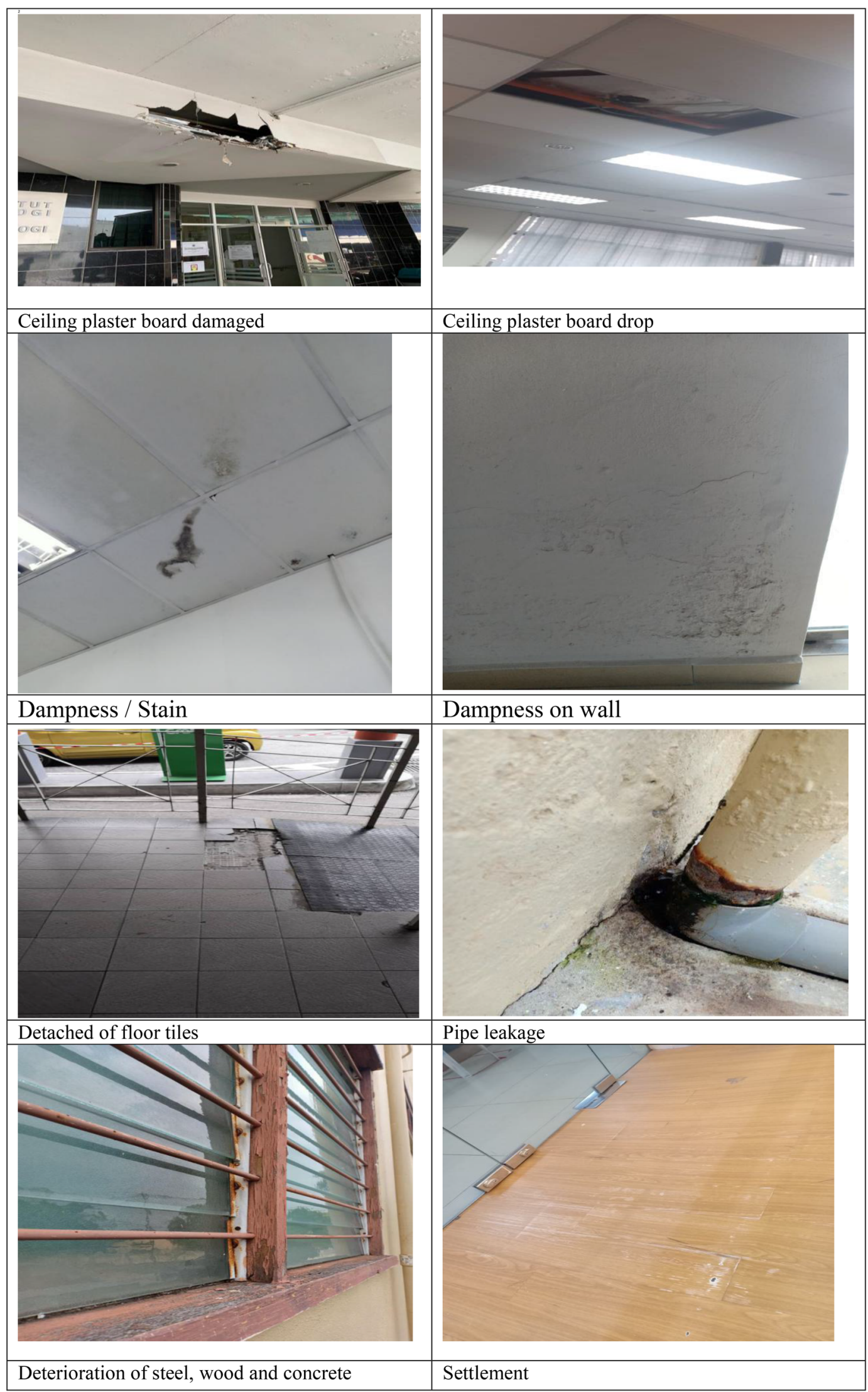

Fig. 3 Types of defects in the hospital buildings 
lighting problems, cracking, and damage to ironmongery are the most common defects in buildings.

One of the main impact of dampness, water seepage, and pipe leakage is discoloured paint. Therefore, it is not surprising that the discolouration of paint in hospital buildings is common and damaging. Damaged plaster boards were also found to be rampant in hospital buildings. Most of the damage was caused by the building's movement, moisture damage, cracks, and loads. One of the interviewees commented that "cracks can be repaired if only minor, but for larger or more heavily damaged areas, it is usually easier and provides a better finish if you replace the affected area." The interviewee also stated that other defects in the hospital include the broken toilet bowl and cover, lighting problems, socket problems, floor trap clogging, and the rusted rooftop. In hospital F, Acrylonitrile Butadiene Styrene (ABS) pipe brittleness and defective water closets (WC) are dominant. Discoloured paint is attributed to the existence of dampness or attack. Other defects also include breaking of roof tiles, ceiling peel off, floor trap clogging, tile breaking, and ceiling peel off. Some of the remedies for defects that were suggested by the interviewees in the hospital buildings include the use of preventive maintenance, educating building users on building operations, improving communication, or methods of making a service request. Additionally, the interviewees suggested that using quality materials and labour during construction and proper planning of the designs are some of the measures that require considerable attention during construction to reduce defects during the building operation phase of the buildings. See also [2].

\subsection{Analyses and discussion of the factors that determine maintenance management in hospital buildings}

Without paying close attention to the design criteria and boosting the maintenance budget, it is unlikely that a complete solution is possible [1,2]. However, it is impossible to conclude that increasing maintenance budgets and spending will improve the building's performance and user satisfaction. This is because, with an increase in the financial allocations alone, maintenance could only be given tactical attention rather than value-based consideration [2]. The latest research in building maintenance management has established the need to focus on the buildings' users in building maintenance management $[4,6]$. Consequently, multiple studies have revealed that a major influencing factor in building maintenance management is the building users $[1,2,5]$. Therefore, it is not surprising that the research found that the users' attitudes (and their requirements) are the major determinant of the maintenance management services in hospital buildings. Hospital building users include patients, hospital staff, medical staff, non-medical staff, and the public. The users often have complex, sophisticated, and conflicting value systems. Considering that hospital buildings are complex, diverse, and sophisticated, users' expectations of hospital buildings are often very high and changing. While the needs and wants of the hospital building users are huge, many of the users misuse the buildings. This may not be surprising, because users (i.e., patients, patients' families, vendors) may not be familiar with the operations of sophisticated hospital buildings and their associated systems. Users also misuse the buildings due to frustration and anger, as Olanrewaju and Abdul-Rashid [6] discovered. It is not surprising to find that weather influence maintenance management. For example, rain may damage roofs, walls, and other building elements. Rain may also delay repair work on defective building components. Humidity and moisture may also influence building maintenance and management. This may influence planning, resource allocation, and implementation of the repair. Weather (rain, temperature, etc.) is the main cause of defects in buildings and is the main factor that affects building maintenance management. Table 5 shows the summary of factors affecting maintenance in healthcare buildings.

Building defects are contagious. Defects will spread to other building components without adequate maintenance. Hence, it is expected that poor maintenance was cited as a major factor influencing the maintenance management of the buildings. Poor maintenance may be the result of a lack of funding to conduct maintenance on time, proper maintenance and a shortage of labour. Poor maintenance may also originate from a lack of information on the nature of the buildings. This explanation is justifiable because the lack of information on the building and the lack of a maintenance register are cited by 4 of the 6 interviewees. The function and design of the building were also cited by most of the interviewees as the main factors that affect the maintenance management of the hospital buildings. As previously explained, the use of the building has a major influence on maintenance management. According to empirical studies,

Table 5 Summary of factors affecting maintenance management

\begin{tabular}{lll}
\hline Factors & Number & Hospital \\
\hline Attitude of user & 6 & $\mathrm{~A}, \mathrm{~B}, \mathrm{C}, \mathrm{D}, \mathrm{E}, \mathrm{F}$ \\
Misuse & 6 & $\mathrm{~A}, \mathrm{~B}, \mathrm{C}, \mathrm{D}, \mathrm{E}, \mathrm{F}$ \\
Insufficient awareness & 4 & $\mathrm{~A}, \mathrm{C}, \mathrm{D}, \mathrm{F}$ \\
Age of building & 3 & $\mathrm{~A}, \mathrm{C}, \mathrm{E}$ \\
Weather & 6 & $\mathrm{~A}, \mathrm{~B}, \mathrm{C}, \mathrm{D}, \mathrm{E}, \mathrm{F}$ \\
Poor maintenance & 6 & $\mathrm{~A}, \mathrm{~B}, \mathrm{C}, \mathrm{D}, \mathrm{E}, \mathrm{F}$ \\
Lack of understanding importance of & 4 & $\mathrm{~A}, \mathrm{~B}, \mathrm{D}, \mathrm{F}$ \\
$\quad$ maintenance work & & \\
Function and design of building & 4 & $\mathrm{~A}, \mathrm{~B}, \mathrm{E}, \mathrm{F}$ \\
Material used during construction & 3 & $\mathrm{~A}, \mathrm{E}, \mathrm{F}$ \\
Construction site (vibration) & 3 & $\mathrm{~A}, \mathrm{D}, \mathrm{E}$ \\
\hline
\end{tabular}


one of the most effective ways to reduce defects [33-35] and improve building maintenance is to simplify the design. Complex designs are difficult to construct and maintain and are expensive to operate. However, modern hospital buildings are design to be complex and aesthetically elegant. It is interesting to find that the age of the buildings is not a major factor that influences the maintenance management of the buildings. However, 2 of the 3 public hospitals cited the age of the building as a critical factor. Buildings, regardless of whether they are used or not, even if constructed with high quality materials, will deteriorate over time [36-38].

\section{Conclusion and advice to hospital maintenance organisation}

The nature of the defects and the factors that affect hospital building maintenance management were explored in this study based on structured interviews. Defects in hospitals come in a variety of shapes and sizes. Moisture is clearly a huge maintenance problems in the hospitals. The agents or consequences of moisture in the building elements include water seepage, pipe leaks, fungus/algae, and discoloured painting. Many of the moisture-related agents and effects can be traced back to design and construction flaws. This appears to back up the interviewees' responses to the question of how to solve defect problems. Ground settlement, concrete deterioration, and humidity are some of the other design/construction issues. Some of the defects in the hospital structures could be due to age or the weather. The majority of the defects in the hospital buildings are structural defects. A thorough inspection and competent workmanship can prevent structural defects. Furthermore, by specifing and procuring high-quality materials for the buildings construction, architectural defects such as discoloured and peeling paint can be avoided. Building maintenance remains the Cinderella of the construction sector and very much to the maintnenace mangement industry. This as the maintenance organisations inherit the design and construction teams' flaws, mistakes, and misdeeds. The maintenance organisations are clearly failing to meet the demands of the users. The maintenance organization's key function is service request management. There is no indication that building users are the primary cause of the defects, contrary to popular estimation from the interviewees. In reality, all hospital maintenance organisations hold the users responsible for a substantial share of the blame or solutions for hospital maintenance due to misuse and attitude. However, this could be as a result of increasing demand by the users for better building performance and maintenance services. The problem is not with the users themselves, but with the way service requests are process. The administration of service requests is a vital role of the maintenance organisation. As a result, the maintenance organisation and procurement procedures must be redesigned to accommodate user requirements.
While this study provided helpful information on hospital building maintenance management, due to the constraints of the structured interview approach, more data may be required to validate the findings. In a structured interview, for example, the interviewer determines the questions asked, not the interviewee, who is free to say what he wants, but there is a risk that the interviewer is not asking the right questions. Furthermore, 10 interviews are the required number of interviews (8-15) to achieve saturation in order to draw valid results based on an interview technique for research. As a result, more research should be conducted with more the sample size. However, some of the hospitals that were interviewed for this study are among Malaysia's best hospitals.

Funding The research has been carried out under Fundamental Research Grant Scheme project FRGS/1/2018/TK06/UTAR/02/ provided by Ministry of Higher Education of Malaysia.

\section{Declarations}

Conflict of interest The authors declare that they have no conflict of interest.

\section{References}

1. Olanrewaju AL, Wong WF, Yahya NNHN, Im LP (2019) Proposed research methodology for establishing the critical success factors for maintenance management of hospital buildings. In AIP conference proceedings, vol 2157(1). AIP Publishing LLC, pp 020036

2. Olanrewaju A, Tee HS, Cheen SK, Jesumoroti OC (2021) Analysis of measures to reduce defects. In: Hospital Buildings. Proceedings of international structural engineering and construction, 8(1), 2021. Interdisciplinary Civil and Construction Engineering Projects. ISSN: 2644-108X. FAM-08. https://doi.org/10.14455/ISEC. 2021.8(1)

3. Olanrewaju A, Fang WW, Tan SY (2018) Hospital building maintenance management model. Int J Eng Technol 7(2.29):747. https://doi.org/10.14419/ijet.v7i2.29.14010

4. Wong WF, Olanrewaju A, Lim PI (2021) Value-based building maintenance practices for public hospitals in Malaysia. Sustainability 13(11):6200

5. Wong WF, Olanrewaju A, Lim PI (2021) Importance and performance of value-based maintenance practices in hospital buildings. Sustainability 13(21):11908

6. Olanrewaju AL, Abdul-Aziz A-R (2015) Building maintenance processes and practices: the case of a fast-developing country. Springer, Berlin

7. Guenther R, Vittori G (2008) Sustainable healthcare architecture. Wiley, New York

8. Ministry of Finance Malaysia (2019) Official Portal of Ministry of Finance Malaysia. https://www.treasury.gov.my/index.php/compo nent $/$ search $/$ searchword $=2019 \&$ searchwordsugg $=\&$ option $=$ com_search. Accessed 30 July 2020

9. NST (New Strait Times) (2017) Health Ministry conducts fire safety audits at 46 hospitals to date

10. NST (New Straits Times) (2011), Hospitals seek help to cut huge electricity bills. N24 
11. The Star (2011) Liow wants staff change: current maintenance team at Penang Hospital is careless says minister, Nation 15

12. The Star Newspaper (2004) Ministries Differ on Fungus Woes at Johor Hospital. 21st October 2004

13. The Star (2017) Upgrades at old hospitals to prevent fires, Nation 27

14. Ulrich RS (2001) Effects of healthcare environmental design on medical outcomes. Design and health: Proceedings of the second international conference on health and design. Svensk Byggtjanst, Stockholm

15. van den Berg A, Wagenaar C (2006) Healing by architecture. The architecture of hospitals. NAi Publishers, Rotterdam, pp 254-257

16. Ali M, Wan Mohamad WMN (2009) Audit assessment of the facilities maintenance management in a public hospital in Malaysia. J Facil Manag 7(2):142-158

17. Omar MF, Ibrahim FA, Omar WMSW (2016) An assessment of the maintenance management effectiveness of public hospital building through key performance indicators. Sains Humanika 1:12. https://doi.org/10.11113/sh.v8n4-2.1059

18. Othman NL, Jaafar M, Harun WMW, Ibrahim F (2015) A case study on moisture problems and building defects. Procedia Soc Behav Sci 170:27-36

19. Rani NAA, Baharum MR, Akbar ARN, Nawawi AH (2015) Perception of maintenance management strategy on healthcare facilities. Procedia Soc Behav Sci 170:272-281. https://doi.org/ 10.1016/j.sbspro.2015.01.037

20. Razak MARMA, Jaafar M (2012) An assessment on faulty public hospital design in Malaysia. J Des Built 5(1)

21. Ong WC, Suleiman Z (2015) Problems in implementation of fire safety management in Malaysia government hospital. Adv Environ Biol 9(4):47-50

22. Ahmed S, Manaf NHA, Islam R (2017) Measuring quality performance between public and private hospitals in Malaysia. Int J Qual Serv Sci 9(2):218-228. https://doi.org/10.1108/ ijqss-02-2017-0015

23. Pakrudin NAA, Abdullah MN, Asmoni M, Mei JLY, Jaafar MN, Mohammed AH (2017) Critical success factors for facilities management implementation in the healthcare industry. Int J Real Estate Stud 11(2):69-83

24. Al-Zubaidi H (1997) Assessing the demand for building maintenance in a major hospital complex. Prop Manage 15(3):173-183

25. Enshassi AA, El Shorafa F (2015) Key performance indicators for the maintenance of public hospitals buildings in the Gaza Strip. Facilities 33(3/4):206-228
26. Jandali D, Sweis R (2018) Assessment of factors affecting maintenance management of hospital buildings in Jordan. J Qual Maint Eng 24(1):37-60

27. Hassanain MA, Assaf S, Al-Ofi K, Al-Abdullah A (2013) Factors affecting maintenance cost of hospital facilities in Saudi Arabia. Prop Manage 31(4):297-310

28. Cohen L, Manion L, Marrison K (2011) Research methods in education, 7th edn. Routledge Publisher, New York

29. Sekaran U, Bougie R (2016) Research methods for business: a skill building approach. Wiley, New York

30. Olanrewaju AL, Idrus A, Khamidi MF (2011) Investigating building maintenance practices in Malaysia: a case study. Struct Surv 29(5):397-410

31. Ismail Z, Isa HM, Takim R (2011) Tracking architectural defects in the Malaysian hospital projects. In: 2011 IEEE symposium on business, engineering and industrial applications (ISBEIA), pp 298-302. IEEE

32. Gómez-Chaparro M, García-Sanz-Calcedo J, Aunión-Villa J (2020) Maintenance in hospitals with less than 200 beds: efficiency indicators. Build Res Inf 48(5):526-537

33. Fisk ER (2003) Construction project management, 7th edn. Prentice-Hall, Upper Saddle River

34. Kelly J, Male S, Graham D (2014) Value management of construction projects. Wiley, New York

35. Olanrewaju AA, Khamidi MF, Idrus A (2010) Building maintenance management in a Malaysian University Campus: a case study. Australas J Constr Econ Build 10(1/2):2010

36. Olanrewaju A, Tan YY, Soh SN (2021) Defect characterisations in the Malaysian affordable housing. Int J Build Pathol Adapt. https://doi.org/10.1108/IJBPA-11-2018-0095

37. Watt DS (2009) Building pathology: principles and practice. Wiley, New York

38. Olanrewaju AA (2013) Revealing the service gaps in building maintenance service delivery: balancing providers' perspectives with users' perspectives. Int J Built Environ Asset Manag $1(2): 121-138$

Publisher's Note Springer Nature remains neutral with regard to jurisdictional claims in published maps and institutional affiliations. 